\title{
Explaining standard retail yields in UK locations
}

Received: 21 October 2003

\begin{abstract}
Naomi Couchman
received her first degree in psychology from City University, London and her Masters in social research and statistics also from City University, London. Naomi has been employed as a research analyst at Jones Lang LaSalle since March 2000. Her main research focus is on the development and application of quantitative techniques to real estate markets utilising both cross-sectional and time-series analysis as an aid to investment decision making. Naomi is a member of the Society of Property Researchers and the European Real Estate Society and a regular presenter at international property research conferences.
\end{abstract}

\section{Sotiris Tsolacos}

is with the UK research team of Jones Lang LaSalle engaging in forecasting work and portfolio strategy. He was previously a lecturer with the Department of Economics at the University of Reading. Sotiris holds a BA in Economics and Econometrics from the University of Athens and MA and PhD degrees from the University of Reading. He has carried out extensive modelling work on real estate markets and has published over 30 papers in major international property research journals. He is also on the editorial board of the Journal of Property Research and sits on the Board of Directors of the European Real Estate Society, of which he was president in 2000-2001.

\section{Abstract}

The empirical investigation of yields across retail centres is an exercise most useful to property investors as it identifies the systematic determinants of retail yield differentials and markets that are over- or under-priced. Yield differentials reflect diverse performance potential and risk factors in individual retail centres. This study estimates a cross-sectional model of UK retail yields in which yield differentials are examined with respect to rent variation and an extensive database containing economic, social and location-specific information. The study finds that two variables, retail footprint scores and occupational classification coding $A B$ most effectively capture the dynamism of local consumer spending power and best explain yield differentials. The analysis also finds that locations at the high or low end of the yield spectrum are not as well explained as those in the middle range. Although there may be factors specific to highand low-yield retail centres, it is suggested that cluster analysis should be explored in over- and under-pricing examinations.

\section{Keywords:}

retail yield differentials, socio-economic and demographic influences, crosssection estimations, under- and over-pricing

\section{INTRODUCTION}

The benefits of geographical diversification to portfolio performance 
Yield pricing

\section{Lack of retail yield studies}

\section{Yield determinants}

are well documented. Once the allocations to sectors are known investors consider geographical locations that meet their criteria in terms of performance outlook, risk and of course pricing. A key issue in this decision-making process is to establish whether locations are correctly priced. Investors invite research that identifies the fundamental factors to explain the current levels of yield and yield differentials across locations. They are particularly interested in information that shows yield differentials deviating from those suggested by the fundamental factors. Therefore, modelling yields across locations on the basis of economic, socio-demographic and property information is seen as a valuable contribution to the pricing of property assets and portfolio decisions.

Despite the importance of studying the structure of yields in locations where there is investment interest, there has been a dearth of relevant research. Research interest seems to concentrate on understanding (and modelling) the movement of yields through time. A Royal Institute of Chartered Surveyors (RICS) study ${ }^{1}$ used a combination of time-series and cross-sectional data to model the retail regional yield gap, defined as the retail regional yield minus the national retail yield, and identified positive and negative influences. But to the best of the authors' knowledge an explicit cross-sectional study of retail yields in the UK is not available. There has been some initial work in this area, for example the crosssectional study of office yields in various UK locations by McGough and Tsolacos, ${ }^{2}$ but there is a clear requirement to expand such empirical investigations to the retail market.

The present study focuses on standard retail yields. In the UK equivalent yields for standard retail units ${ }^{3}$ varied between 6.4 per cent in Cambridge, Chester, Cardiff, Edinburgh, Leeds and Nottingham to 9.1 per cent in Wakefield. Wakefield was the only location to report an equivalent yield of over 9 per cent in 2002, although eight locations reported equivalent yields of 8 per cent or more. This range in yields reflects the variation in the expectations of market participants for future performance and perception of risk factors for standard retail units in each location. The performance and the associated risks of the standard retail market at the local level reflects interactions of a number of local attributes, comprising local economic factors, socio-demographic characteristics, local property market conditions and other contributors.

Data series describing these factors are indicators of the strengths of the local consumer spending and retailing environment and are employed to investigate the determinants of standard retail yields across UK centres. More specifically the aims of the study are:

- to identify factors which best explain yields in standard retail centres and account for yield differentials in UK locations

- to provide information on centres that are potentially overvalued and undervalued, and as a result centres in which the risk premia are overstated or understated 


\section{Research challenges}

Data used

Location characteristics

Regression analysis
- to illustrate the potential and the implications of deploying cross-sectional methodologies which are commonly used approaches in this type of analysis.

The availability of more detailed databases for the locality containing economic, demographic, occupational and social trends data improves an analysis focusing on location pricing and poses challenges to property researchers. It is important that property researchers investigate the usefulness of the additional data for pricing purposes. This line of research is expected to identify the series that are relatively more important for the purpose of yield modelling. This is likely to provide a further incentive for the compilation of these data and in a larger number of locations, including outside the UK. The wealth of data will enable researchers to develop more testable hypotheses.

The remainder of the paper contains three sections. The following section outlines the methodology and describes the data used to capture the determinants of retail yields. Section three presents the results of the cross-sectional analysis. The final section concludes and draws upon the implications of this study.

\section{METHODOLOGY AND DATA}

The data for the standard retail equivalent yields are taken from the Investment Property Databank (IPD) Key Centres Database. ${ }^{4}$ This database contains 65 retail locations. The yield differentials in these standard retail centres are modelled on 42 variables, which fall in the following broad categories:

- economic: at both county level and local authority district level $(\mathrm{LAD})^{5}$

- property related

- salary related

- demographic

- socio-demographic.

A full description and the sources of data are given in the Appendix.

These categories of 'explanatory' variables convey information about the strength of consumer spending in the area and retail business conditions. (Insight as to which factors might be affecting retail yields at the local level can be gained from studies on crosssection retail determination. The location-specific characteristics this literature identifies includes economic and demographic measures, the presence of anchor tenants and accessibility - see for example Sirmans and Guidry. ${ }^{6}$ ) The empirical investigation takes the form of regression analysis to identify the variables that are most successful in explaining standard retail yields across the 65 locations. For this purpose two separate methodologies were deployed: a stepwise regression and a 'general-to-specific' approach. According to the 


\section{Stages in the empirical investigation}

\section{Determinants of yield variation}

\section{Outliers in the model}

first methodology the final model contains a combination of variables which maximise the explanatory power of the model (represented by the adjusted R-squared statistic), ie the model that explains most of the yield variation. The second methodology applies a number of criteria to select the variables that enter the final model: the sign of the coefficient of each variable is as expected; the variables are statistically significant at the 10 per cent level; and inclusion of additional variables into the model decreases the value of the Akaike information criterion (this is a criterion that imposes a penalty - and its value rises - if the additional variables are superfluous).

The empirical investigation is carried out in three stages. In the first stage information is obtained about the performance of each of the 42 indicators in explaining yields. In the second stage the most successful variables are combined to generate a more general model of yields. The estimated yields produced from this model will be compared to the actual yield in 2002 (published in the IPD Key Centres Database, $2003^{7}$ ) in order to make comparisons and draw conclusions. In the third stage a further investigation is carried out to determine whether the results vary across low- and high-yield retail centres and by the size of the retail centre.

\section{RESULTS}

\section{Stage 1}

The first part of the analysis that aimed to provide evidence on the significance of each of the 42 variables revealed some interesting results. A notable finding is that the variation in standard retail rents is not statistically significant - that is, the variation in the level of rent and the growth rate cannot explain the yield gaps between locations. Perhaps rents do not capture the influences that underpinned yield differentials in 2002. Further testing needs to be conducted in previous years in order to provide more concrete evidence. This should also be monitored in the future. But the weak relationship between rent differentials and yield differentials was also a finding in the study of McGough and Tsolacos ${ }^{8}$ in the office sector. Similarly, with the exception of GDP growth per capita, this investigation did not provide support in establishing a significant relationship between yield variation and economic variables measured at the county level. On the other hand, most of the economic variables at the local authority district (LAD) level were significant along with the majority of socio-demographic variables.

The explanatory power, measured by the adjusted R-squared statistic (adjusted $\mathrm{R}^{2}$ ), of the significant variables ranged from 7 per cent to 24 per cent. In cross-sectional studies an adjusted $\mathrm{R}^{2}$ of over 20 per cent for individual variables represents a satisfactory performance. This is because even a small number of outliers - that is locations that cannot be explained well by the regression analysis - can affect the value of the adjusted $\mathrm{R}^{2}$. The variables with the 
highest explanatory power (over 20 per cent) were:

- proportion of the LAD population earning more than $£ 30,000$ per annum but less than $£ 40,000$ per annum (see note $\mathrm{c}$ in Appendix)

- proportion of the LAD population earning more than $£ 40,000$ per annum but less than $£ 50,000$ per annum (see note $\mathrm{c}$ in Appendix)

- proportion of the LAD population earning more than $£ 50,000$ per annum (see note $\mathrm{c}$ in Appendix)

- total retail expenditure in each LAD (see note $b$ in Appendix)

- retail footprint score of each LAD (see note $h$ in Appendix)

- proportion of the LAD population classified as being in occupational class $\mathrm{AB}^{9}$ (see note $\mathrm{g}$ in Appendix)

- proportion of the LAD population classified as being in occupational class CII. ${ }^{10}$ (see note g in Appendix)

\section{Stage 2}

In the second part of the analysis all variables that were individually statistically significant were combined in an attempt to find a final model that would contain a combination of these variables. The methods employed are the 'stepwise' regression and the general-to-specific regression as described in the previous section. The results of these multivariate linear regression analyses found two model solutions, both of which passed standard diagnostic tests for robustness.

The first model included the retail footprint score variable

\section{Retail footprint score}

\section{Occupational class AB}

(RF_Score). The RF_Score is a retail performance indicator compiled by CACI. ${ }^{1{ }^{1}}$ The variable is a score assigned to various comparison retail centres throughout the UK. The retail footprint calculates 'shopper populations' based on the quantity and quality of the retail centre. Larger footprints are given to larger centres (it is assumed that the larger the centre the more attractive) and those with greater ease of accessibility (calculated by a combination of distance and time). It aims to understand the demographics of each retail centre's catchment based on expenditure and the number of shoppers who visit it (distinguished from nearby residents who may shop elsewhere). This was the only variable included in the model, as its significance was so strong that it stripped all other variables of their significance. This means that it did a better job of explaining yield variation across the 65 UK retail centres than an alternative model which seeks to group all variables marked as significant in the first stage of the analysis.

For the same reasons as stated above, the second model also included a single variable, the proportion of the LAD population classified into occupational class AB (AB_Class). This class refers to professional and managerial workers, representing 37 per cent of the UK population. It was not possible to group both RF_Score and AB_Class together in the same model as they counteracted each 
Predicted vs Actual

\section{Undervalued and overvalued locations}

\author{
Interpretation of \\ results
}

other, thus both becoming insignificant. These findings suggest the presence of multicollinearity. This arises when two or more variables capture similar influences. Therefore RF_Score and AB_Class appear to be alternative but close measures of the same influences on yields. Moreover, the variable which measures the proportion of the LAD population earning more than $£ 30,000$ but less than $£ 40,000$ per annum highly correlates with AB_Class. This is hardly surprising, since those classified as AB_Class are most likely to earn more than $£ 30,000$ per annum. When these variables are simultaneously included in the model however, the statistical criteria for variable selection chose the most dominant variable, namely AB_Class.

The differences between the actual equivalent yield in 2002 and that predicted by the two statistical models - the first containing the variable AB_Class and the second containing the variable RF_Score - are given in Table 1. This table shows the locations that are best explained by these two most successful variables and provides a guide to potential overpriced and underpriced standard retail locations.

In certain markets such as Northampton the predicted values are very close to the actual values for both variables. In 2002 the standard retail equivalent yield in Northampton was 7.3 per cent and both models predict 7.3 per cent. In other markets the two models fail to be so successful. For example the actual equivalent yield in Oxford was 6.5 per cent whereas both models predict 7.3 per cent. Perhaps in locations such as Oxford other parameters over and above RS_Score and AB_Class may be important in explaining the level of yields.

The findings in Table 1 can also be used to identify centres that are potentially overvalued or undervalued. A centre is considered undervalued (ie opportunistic) if it has an actual equivalent yield (in 2002) which is higher than that predicted by either or both of the regression models. A centre is considered overvalued if it has an actual equivalent yield which is lower than that predicted by the models. There is no rule, however, as to what differentials between the actual and predicted yield indicate mispricing: the larger the gap the stronger the indication. Given that this analysis has established two competing models another rule could be added — that the centre appears overvalued or undervalued on the basis of both models. For example in Reading the regression model containing the variable AB_Class suggests a yield of 6.7 per cent whereas the model containing the variable RF_Score suggests a yield of 7.0 per cent. These compare with the actual equivalent yield in 2002 of 6.9 per cent. The results for Reading are therefore inconclusive.

On the basis of these criteria Derby standard shop yields appear lower than the predicted yields, suggesting this centre is overvalued. On the other hand the actual yield in Glasgow is higher than the predicted yield, signifying the possibility of undervaluation. It is important to note here that these are indications of underpricing or 
Table I: Estimation results - Actual and predicted equivalent yields for standard retail centres

\begin{tabular}{|c|c|c|c|}
\hline Location & Actual & $\begin{array}{l}\text { Predicted model containing } \\
\text { variable AB_Class }\end{array}$ & $\begin{array}{l}\text { Predicted model containing } \\
\text { variable RF_Score }\end{array}$ \\
\hline Aberdeen & 6.9 & 7.2 & 7.0 \\
\hline Barnet & 8.6 & 7.7 & 7.8 \\
\hline Bath & 7.2 & 7.4 & 7.2 \\
\hline Birmingham & 7.3 & 6.6 & 6.8 \\
\hline Bolton & 8.4 & 7.3 & 7.3 \\
\hline Bournemouth & 7.2 & 7.4 & 7.4 \\
\hline Brighton & 7.1 & 6.9 & 6.6 \\
\hline Bristol & 7.4 & 6.9 & 7.1 \\
\hline Bromley & 7.0 & 7.2 & 7.3 \\
\hline Cambridge & 6.4 & 7.0 & 7.1 \\
\hline Cardiff & 6.4 & 6.9 & 7.1 \\
\hline Cheltenham & 7.2 & 7.4 & 7.2 \\
\hline Chester & 6.4 & 7.2 & 7.2 \\
\hline Chichester & 7.2 & 7.6 & 7.5 \\
\hline Colchester & 7.4 & 7.4 & 7.3 \\
\hline Croydon & 7.3 & 7.0 & 7.1 \\
\hline Darlington & 7.9 & 7.6 & 7.5 \\
\hline Derby & 6.7 & 7.3 & 7.4 \\
\hline Eastbourne & 7.9 & 7.5 & 7.5 \\
\hline Edinburgh & 6.4 & 6.9 & 6.9 \\
\hline Exeter & 7.0 & 7.3 & 7.3 \\
\hline Glasgow & 6.7 & 6.3 & 6.0 \\
\hline Gloucester & 8.0 & 7.5 & 7.4 \\
\hline Guildford & 6.8 & 7.1 & 7.2 \\
\hline Harrogate & 7.2 & 7.5 & 7.5 \\
\hline Harrow & 7.2 & 7.4 & 7.5 \\
\hline Hounslow & 7.8 & 7.6 & 7.6 \\
\hline Ipswich & 6.9 & 7.3 & 7.3 \\
\hline Kingston-upon-Thames & 6.5 & 7.1 & 7.2 \\
\hline Lancaster & 7.0 & 7.7 & 7.6 \\
\hline Leeds & 6.4 & 6.6 & 6.7 \\
\hline Leicester & 6.7 & 6.9 & 7.0 \\
\hline Lincoln & 7.0 & 7.4 & 7.4 \\
\hline Liverpool & 6.7 & 7.1 & 7.0 \\
\hline Macclesfield & 8.3 & 7.6 & 7.6 \\
\hline Maidstone & 6.9 & 7.3 & 7.4 \\
\hline Manchester & 6.9 & 6.5 & 6.6 \\
\hline Middlesbrough & 6.9 & 7.4 & 7.3 \\
\hline Newcastle-upon-Tyne & 6.6 & 7.0 & 6.9 \\
\hline Northampton & 7.4 & 7.3 & 7.3 \\
\hline Norwich & 7.5 & 6.9 & 7.0 \\
\hline Nottingham & 6.4 & 6.6 & 6.7 \\
\hline Oxford & 6.5 & 7.3 & 7.3 \\
\hline Plymouth & 8.3 & 7.4 & 7.2 \\
\hline Portsmouth & 7.1 & 7.6 & 7.5 \\
\hline Preston & 7.8 & 7.3 & 7.3 \\
\hline Reading & 6.9 & 6.7 & 7.0 \\
\hline Salisbury & 7.8 & 7.6 & 7.5 \\
\hline Sheffield & 7.6 & 7.1 & 7.1 \\
\hline Shrewsbury & 7.0 & 7.6 & 7.4 \\
\hline Slough & 7.7 & 7.4 & 7.5 \\
\hline Southampton & 7.6 & 7.0 & 7.2 \\
\hline Southend-on-Sea & 8.0 & 7.5 & 7.5 \\
\hline St Albans & 7.8 & 7.4 & 7.6 \\
\hline Stoke-on-Trent & 8.1 & 7.4 & 7.4 \\
\hline Sutton & 7.0 & 7.5 & 7.5 \\
\hline Swansea & 8.1 & 7.4 & 7.3 \\
\hline Tunbridge Wells & 6.7 & 7.4 & 7.4 \\
\hline Wakefield & 9.1 & 7.6 & 7.5 \\
\hline Watford & 7.6 & 7.2 & 7.2 \\
\hline Winchester & 7.2 & 7.6 & 7.6 \\
\hline Windsor & 7.8 & 7.6 & 7.5 \\
\hline Wolverhampton & 6.7 & 7.3 & 7.1 \\
\hline Worcester & 6.9 & 7.4 & 7.3 \\
\hline York & 6.7 & 7.3 & 7.2 \\
\hline
\end{tabular}


Forecast patterns in low- and high-yield locations overpricing. The disparities in the predicted and actual values may be the result of the local specific factors. If these factors are present in only a few cities they cannot be considered as systematic influences. Systematic determinants of yields across locations are those identified by the analysis using the full sample. In the light of the discrepancies between realised and predicted equivalent yields, local market research and information should be utilised to explain the gap. If such information is available and does not justify the actual predicted yield gap, the investor has a strong signal of mispricing.

\section{Stage 3}

The results of this analysis are now examined in high- and low-yield centres and in small and large retail centres. In order to address how successful the models are in explaining yields in high- and lowyield locations the actual and predicted yields are plotted from the lowest to the highest yield, as shown in Figure 1.

Figure 1 also contains two boundaries showing the actual yield as $+/-10$ per cent in each of the locations. Taking the boundary as 10 per cent of the actual yield is an arbitrary way in which to illustrate the size of the errors. The analyst could use tighter boundaries, say 5 per cent of the actual error. It appears that nearly all predictions of the model containing the variable RF_Score are within the 10 per cent boundary. But a pattern emerges. At the low end of the yield spectrum, the predicted values tend to be above the actual yields, suggesting overvaluation. At the other end of the spectrum predicted yields tend to be lower than actual yields, indicating undervaluation. The model seems to be consistent in the middle ranges. There may be several reasons for this pattern, including the fact that different variables explain yields at the low and high end of the yield spectrum. The authors' suggestion is that

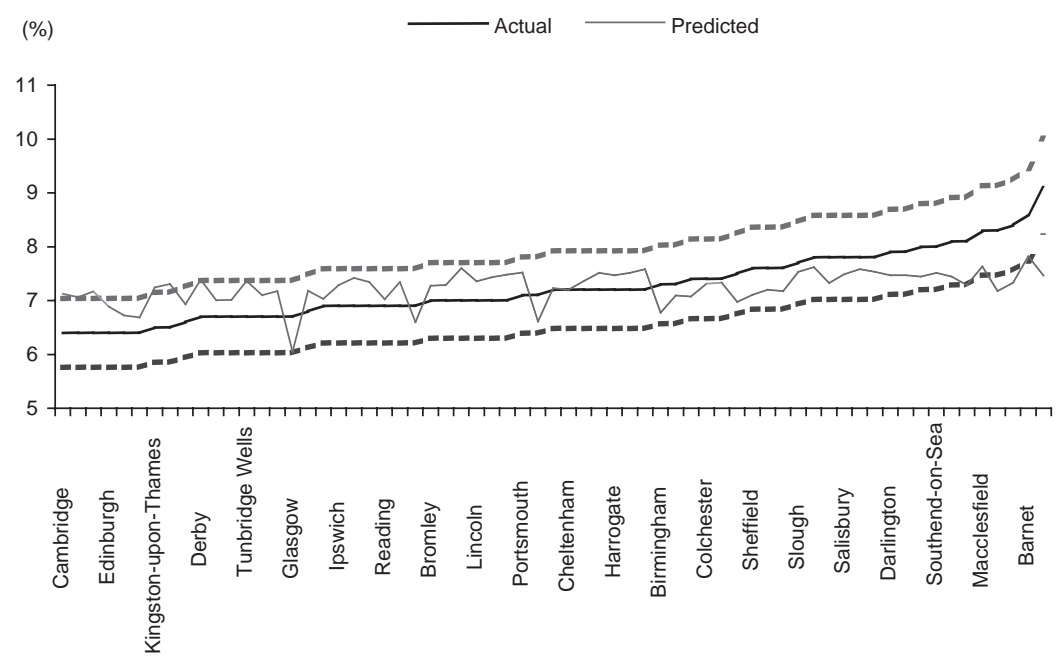

Figure 1: Actual and predicted yields in low- and high-yield centres (RF_Score model) 


\section{Need for cluster analysis}

\section{Forecast patterns in small and large centres}

Inconclusive findings

\section{Empirical evidence on pricing issues}

a further statistical technique called cluster analysis should be performed in addition to the existing methodology. Cluster analysis seeks to classify locations according to similar, shared characteristics. Locations are based on their 'nearness' by measuring distances of similarity or dissimilarity. Therefore if locations are clustered according to similarity of yields, a further technique called principal components analysis may be applied in an effort to identify determinants of these clusters at either end of the yield spectrum. Similarly, the model containing the AB_Class variable presents the same picture.

The hypothesis of whether the size of the retail centre bears any relation to whether it is overvalued or undervalued is next examined. The reasoning behind this is that many of the larger retail centres are now perceived as being overpriced. This is due to profit margins that continue to be squeezed, pricing many retailers out of larger markets. In addition, increased congestion around many of these centres has led to the perception that secondary locations are now becoming more attractive. Such locations should be identified as being smaller and undervalued.

Retail centres were categorised as being large or small based upon total retail floor space. The average-sized retail centre across all 65 locations was estimated to be $1,324,752 \mathrm{~m}^{2}$ (calculated by taking the arithmetic mean of the floor space of all 65 retail centres). Subsequently centres in the vicinity of the mean were excluded in order to make the difference between smaller and larger centres more clearly defined. All centres whose size fell within 10 per cent of the arithmetic mean were excluded (centres with sizes between $1,192,277 \mathrm{~m}^{2}$ and $1,457,228 \mathrm{~m}^{2}$ ). This left 27 small centres and 23 large centres.

The estimates obtained from the regression model containing the variable RF_Score indicate that 12 of the 23 large centres are overvalued and 13 of the 27 small centres are undervalued. These findings are inconclusive and further testing is needed to determine whether there is a significant relationship between size and mispricing. It should also be noted that results are subject to the way in which the analyst groups small and large centres.

\section{SUMMARY AND CONCLUSIONS}

This study examines standard retail yield differentials across 65 centres in the UK using data from the IPD's Key Centres database. ${ }^{12}$ The objective is to offer empirical evidence that can be used as an input to standard retail pricing in the UK. Yield differentials are the product of the varying dynamism of the local economy, the business of retailing and the standard retail market. This research attempts to capture the strength of local retailing with a large set of economic, socio-demographic and other variables. The information these variables contain is measured at both the county level and the LAD level. Given the dearth of studies of retail yields, the present study addresses several issues that are of 
importance for pricing, determining risk premia and investment decisions.

The implications of the findings are multiple. Investors could obtain important information about standard retail yields that is conveyed by the different RF_Score and the proportion of each LAD population classified as occupational class AB (AB_Class). These variables are identified by the analysis as key systematic influences on equivalent yields across standard shop locations. The analysis also suggests that these two factors are better predictors of yields in the middle range of the yield spectrum. It is suggested that further research utilising cluster analysis and principal factor analysis should be undertaken to examine whether systematic influences are relevant in the lower and higher ends of the yield spectrum. Finally, the analysis did not offer strong support to the argument that larger centres are overpriced given the cost pressures on retailers and the impacts of congestion.

The greater availability of local market data should be utilised through cross-sectional studies for the purpose of studying yield differentials and hence risk premia among locations. For betterinformed decisions such research should be repeated over time to observe whether overpriced or underpriced locations tend to move towards the values predicted by the models containing the systematic influences. The analysis then becomes more complicated as there may be national factors that could drive all yields in one direction, which has been the experience in the last two to three years in most sectors. But no one expects modelling yields to be an easy exercise.

\section{ACKNOWLEDGMENT}

The authors are grateful to Melanie Bayliff for the data support she provided to them.

\section{APPENDIX: RANGE OF VARIABLES USED IN THE ANALYSIS}

\section{County economic variables ${ }^{\mathrm{a}}$}

GDP

GDP per capita

Total employment

Output in retailing

Employment in retail

Household disposable income

Household disposable income per capita

Household spending

Household spending per capita

Claimant count unemployment

\section{Local economic variables ${ }^{b}$}

Total clothing expenditure (£m)

Total footwear expenditure (£m)

Total expenditure on household goods and textiles $(£ \mathrm{~m})$

Total retail expenditure $(£ \mathrm{~m})$ 


\section{Salary variables ${ }^{c}$}

Earning more than $£ 50,000$ pa

Earning more than $£ 30,000$ pa

and less than $£ 40,000$ pa

Earning more than $£ 20,000$ pa

and less than $£ 30,000$ pa

Earning more than $£ 10,000$ pa

and less than $£ 20,000$ pa

Earning less than $£ 10,000$ pa

\section{Demographic variables ${ }^{\mathrm{f}}$}

Population (000s) in 2002

Population aged 15-24

Population aged 25-44

Population aged 45-64

Population aged 65 and over

\section{Property variables}

IPD retail rental index $2002^{\mathrm{d}}$

Total comparison floor space

Retail floor space

Retail footprint score ${ }^{\mathrm{h}}$

\section{Socio-demographic variables ${ }^{\mathrm{g}}$}

People classified as 'thriving'

People classified as 'expanding'

People classified as 'rising'

People classified as 'settling'

People classified as 'aspiring'

People classified as 'striving'

People classified as class AB

People classified as class $\mathrm{C} 1$

People classified as class $\mathrm{C} 2$

People classified as class DE

People who have no car

People who have one car

People who have two cars

People who have three cars

a. Economic variables at the county level are sourced from Experian Business Strategies Regional Planning Service and refer to 2002 figures (see www.business-strategies.co.uk/ sharedresearch/rps). Data are measured in absolute totals (£m, 1995 prices) and also percentage growth from 2001 to 2002.

b. Local economic variables are sourced from CACI Information Solutions and refer to 2002 figures (see www.caci.co.uk). Data are measured at the local authority district (LAD) level in absolute totals (£m) and also percentage growth from 2001 to 2002.

c. Salary variables are sourced from CACI Information Solutions, refer to 2002 figures and are collected at the LAD level. Data are measured in absolute totals (total number of people) and also the proportion (percentage) of the LAD population.

d. IPD retail rental index 2002 data are sourced from the IPD Key Centres Database 2003 (see www.ipdindex.co.uk). Data are collected at the LAD level. The Investment Property

Databank publishes this data as an index $(1980=100)$. The authors' estimates use the index value in 2002 and the percentage change in the index from 2001 to 2002.

e. Floor-space statistics are sourced from the GOAD database and refer to 2002 data measured at town level (see www.micromarketing@experian.com). Comparison floor space is measured in both absolute totals $\left(\mathrm{m}^{2}\right)$ and also as a proportion (percentage) of total retail floor space.

f. Demographic variables are sourced by Acorn Classification Systems 2001(see www.caci.co.uk). The variables are measured in absolute totals (total number of people in each LAD) and the proportion (percentage) of the LAD population. 
g. Socio-demographic variables are sourced by Acorn Classification Systems (see www.caci.co.uk). The affluence classification system is a measure of affluence and aims to depict the dynamism of Great Britain's population by grouping them into different neighbourhood types according to the type of residential area in which they live. This is based on the assumption that individuals who inhabit similar neighbourhoods are also likely to have similar behaviour, purchasing and lifestyle habits. Acorn's six groupings of affluence are defined as thriving, expanding, rising, settling, aspiring and striving. The occupational class groupings are based on the 1990 edition of the standard occupational classification. Classes are ordered from the highest skilled to the lowest skilled, with class AB representing professionals and top management and class DE representing unskilled labourers. All the socio-demographic variables (including the car ownership variables) are measured in absolute totals (total number of people in each LAD) and the proportion (percentage) of the LAD population.

$\mathrm{h}$. The retail footprint score is a performance indicator compiled by CACI Information Solutions 2002. The variable is a score assigned to various comparison retail centres throughout the UK. The retail footprint calculates 'shopper populations' based on the quantity and quality of the retail centre. Larger footprints are given to larger centres (it is assumed that the larger the centre, the move attractive) and those with greater ease of accessibility (calculated by a combination of distance and time). It aims to understand the demographics of each retail centre's catchment based on expenditure and the number of shoppers who visit it (distinguished from nearby residents who may shop elsewhere).

\section{References and Notes}

1. RICS (1994) Understanding the Property Cycle, Royal Institution of Chartered Surveyors, London.

2. McGough, T. and Tsolacos, S. (2002) 'A cross-sectional study of office yields in the UK', paper presented at the 18th American Real Estate Society Conference, Naples, USA, 1013 April.

3. Investment Property Databank (2003) Key Centres Database, http://www.ipdindex. co.uk, 2003.

4. The equivalent yield for any given location refers to the average equivalent yield of a number of standard retail units held as standing investments in portfolios throughout the year in each LAD. Standing investments refer to properties valued and held within the portfolio throughout the calendar year. Equivalent yields refer to December values each year. Properties that are owner occupied or developments are specifically excluded from the IPD sample to ensure easy comparison across markets.

5. The local authority district is an elected corporate body that is responsible for the administration of specific public services to the community in a defined area. These bodies include county councils and district councils.

6. Sirmans, C. and Guidry, K. (1993) 'The determinants of shopping center rents', Journal of Real Estate Research, Vol. 8, No. 1, pp. 107-115.

7. Investment Property Databank, ref. 3 above.

8. McGough and Tsolacos, ref. 2 above.

9. CACI Information Solutions (2002). Occupation class AB refers to professional and managerial workers (representing 37 per cent of employees in Great Britain).

10. Ibid. Occupation class CII refers to skilled manual workers (representing 26 per cent of employees in Great Britain).

11. Ibid.

12. Investment Property Databank, ref. 3 above. 